\title{
Prediction of local scour around wide bridge piers under clear-water conditions
}

\begin{abstract}
Local scour is the removal of sediment from around bridge piers due to flowing of water. A large amount of local scour is dangerous to the bridge piers and causes the structure tend to collapse and loss of life without any warning. Many researchers have already investigated the phenomenon of local scour around bridge piers. The literature search revealed that there is very little information on predictive equations or data on scour around wide piers. Most of the predictive equations in the literature are intended to apply equally well to large and small piers. Hence, this leads to a situation in which design is prioritised over prediction, which thus proves costly and economically inefficient. This study attempted to fill this gap where new experimental data from a physical model of scouring around a cylindrical and rectangular wide pier embedded in two types of uniform sediment beds are presented. The effects of sediment sizes and various pier widths on equilibrium scour depth of wide bridge piers are described. New empirical relation for the estimation of non-dimensional maximum scour depth for a wide pier were proposed as functions of the sediment coarseness. The experimental data obtained in this study and data available from the literature are used to validate the predictions of existing methods and the accuracy of the proposed method. The proposed method gives reasonable scour depth predictions and was verified with statistical methods where the root mean square error was reduced from $71 \%$ to $26 \%$. The new empirical relation agrees satisfactorily with the experimental data.
\end{abstract}

Keyword: Local scour; Wide piers; Equilibrium scour; Existing equations; Scour prediction 